\title{
Spatiotemporal Description of Epidemics Caused by Phoma ligulicola in Tasmanian Pyrethrum Fields
}

\author{
Sarah J. Pethybridge, Paul Esker, Frank Hay, Calum Wilson, and Forrest W. Nutter, Jr.
}

First and third authors: Tasmanian Institute of Agricultural Research (TIAR), University of Tasmania, P.O. Box 3523, Burnie, Tasmania, 7320, Australia; second and fifth authors: Department of Plant Pathology, Iowa State University, Ames 50011; and fourth author: TIAR, New Town Research Laboratories, 13 St. Johns Ave., New Town, Tasmania, 7008, Australia. Accepted for publication 15 February 2005.

\begin{abstract}
Pethybridge, S. J., Esker, P., Hay, F., Wilson, C., and Nutter, F. W., Jr. 2005. Spatiotemporal description of epidemics caused by Phoma ligulicola in Tasmanian pyrethrum fields. Phytopathology 95:648-658.

Spatial and temporal patterns of foliar disease caused by Phoma ligulicola were quantified in naturally occurring epidemics in Tasmanian pyrethrum fields. Disease assessments (defoliation incidence, defoliation severity, incidence of stems with ray blight, and incidence of flowers with ray blight) were performed four times each year in 2002 and 2003. Spatial analyses based on distribution fitting, runs analysis, and spatial analysis by distance indices (SADIE) demonstrated aggregation in fields approaching their first harvest for all assessment times between September and December. In second-year harvest fields, however, the incidence of stems with ray blight was random for the first and last samplings, but aggregated between these times. Spatiotemporal analyses were conducted between the same disease intensity measures at subsequent assessment times with the association function of SADIE. In first-year harvest fields,

the presence of steep spatial gradients was suggested, most likely from dispersal of conidia from foci within the field. The importance of exogenous inoculum sources, such as wind-dispersed ascospores, was suggested by the absence of significant association between defoliation intensity (incidence and severity) and incidence of stems with ray blight in second-year harvest fields. The logistic model provided the best temporal fit to the increase in defoliation severity in each of six first-year harvest fields in 2003. The logistic model also provided the best fit for the incidence of stems with ray blight and the incidence of flowers with ray blight in four of six and three of six fields, respectively, whereas the Gompertz model provided the best fit in the remaining fields. Fungicides applied prior to mid-October (early spring) significantly reduced the area under disease progress curve $(P<0.001)$ for defoliation severity, the incidence of stems with ray blight, and the incidence of flowers with ray blight for epidemics at all field locations. This study provides information concerning the epidemiology of foliar disease and ray blight epidemics in pyrethrum and offers insight on how to best manage these diseases.
\end{abstract}

Pyrethrum (Tanacetum cinerariaefolium L.) is a perennial plant belonging to the Compositae family and its flowers are grown commercially in Tasmania, Australia for the natural production of pyrethrin insecticide (6). Pyrethrin is a key ingredient in domestic insect repellent products and pet flea collars. Pyrethrum is of significant importance to Tasmanian agriculture and currently contributes $\approx \mathrm{AU} \$ 25$ million to the Australian economy annually. The commercial life span of a pyrethrum field in Tasmania is 5 years. The time between termination and replanting the same field back into pyrethrum is $\approx 4$ years. Fields are planted between July and September, and it is $\approx 18$ months before the first harvest occurs.

Since 2000, Phoma ligulicola Baker, Dimock \& Davis var. Arx has been responsible for severe annual epidemics of foliar dieback in Tasmanian pyrethrum fields. This disease was first described in 1995 on flowers and buds (37), and subsequently found to cause a variety of symptoms on leaves and emerging flowering stems (34). Epidemics typically occur in early spring in Tasmania (August and September) and, without proper and timely management, can result in the total loss of whole fields (35). Symptoms on leaves begin as necrotic spots, which then enlarge and coalesce to asymmetrically encompass the entire leaf surface. The fungus often invades the petiole and then initiates necrosis in stems. The "ray blight" phase of this pathosystem begins as a necrotic lesion that expands to $\approx 20$ to $30 \mathrm{~mm}$ on the peduncle below the un-

Corresponding author: S. J. Pethybridge; E-mail address: sarah_jp@utas.edu.au

DOI: 10.1094/PHYTO-95-0648

(c) 2005 The American Phytopathological Society opened bud, resulting in a "shepherd's crook" appearance of the diseased peduncle. A severe form of ray blight also can manifest in young plants approaching their first year of harvest. In these plants, the flowering stem becomes severely distorted, shoots and developing buds become necrotic, and the necrosis may extend the entire length of the stem. These symptoms first were observed in Tasmanian production fields in August and September 2000. Similar symptoms and levels of disease intensity also have been described in California, where the disease has been present since 1949 (2); however, severe leaf and stem lesions were not reported until 1959 (1). Pycnidia of $P$. ligulicola frequently are observed in necrotic tissues of affected plants $(34,37)$; however, the teleomorph stage, Didymella ligulicola, has not yet been observed in Tasmania $(2,38,45)$. P. ligulicola also may be introduced into crops by epiphytic mycelium (7), Compositae hosts $(8,38)$, and pseudosclerotia within soil (4). Infested seed is believed to be the source of primary inoculum in Tasmanian pyrethrum fields (S. J. Pethybridge, unpublished data).

Description of the spatiotemporal characteristics of epidemics provides valuable information on pathogen dissemination and epidemic progress, which is lacking in the pyrethrum- $P$. ligulicola pathosystem. This information is needed to test quantitative hypotheses to determine the introduction and source or sources of inoculum into a pyrethrum field, the presence and relative role of the teleomorph in epidemic development, and the design and implementation of effective sampling strategies for this disease (17). This information also is important in order to make the most effective management recommendations, currently centered on the strategic application of fungicides in early spring, to reduce the risk of foliar dieback annually. Quantitative spatiotemporal information also helps in the prediction of plant disease losses (41, 
42). The key goal of spatiotemporal description is to hypothesize physical and biological mechanisms influencing disease development in time and space, and to simplify the multidimensional attributes of the epidemic. Tools for the depiction of spatial disease patterns fall into two general classes, point-pattern $(5,9,10$, $23,40,43)$ and correlation-based analyses $(9,10,13,24-26,39,43)$, which quantify spatial pattern on different scales $(41,42)$. The spatial analysis by distance indices (SADIE) method developed by Perry $(30,31)$ also belongs to the latter group of analyses. However, this method also takes into account the inherent heterogeneity within the dataset like those in the point-pattern class of techniques (23).

Temporal progression of an epidemic can be described and quantified by fitting disease progress models $(20,28)$. Polycyclic diseases often are best described by either the logistic or the Gompertz population growth models, whereas monocyclic diseases can best be described by the monomolecular model $(5,28$, $29,43,44)$. However, the spatiotemporal attributes of an epidemic can be characterized using an extension of SADIE (46). This process compares the clustering indices generated from SADIE as measures of local spatial association over two consecutive time periods to quantify overall association $(X)$. Clustering indices measure the net distance that individuals are required to travel at each sampling unit to achieve regularity (33). This is analogous to the use of clustering indices to determine the spatial association between two species $(32,36,46)$. Spatiotemporal association, therefore, implies expansion of existing foci, whereas the absence of significant associations between two time periods implies an external (outside the field) source of inoculum as a mechanism to generate new disease foci within the field.

The objectives of this study were to (i) quantify the spatial pattern disease caused by $P$. ligulicola in Tasmanian pyrethrum fields and the association among different types of disease intensity measures, (ii) characterize and quantify the temporal progression of P. ligulicola epidemics, (iii) quantify the spatiotemporal relationships between successive disease assessment periods, and (iv) examine the efficacy and impact of commonly used fungicides in reducing disease intensity and increasing the dollar return on investment.

\section{MATERIALS AND METHODS}

Field sites and data collection for spatial analyses. Naturally occurring epidemics in two pyrethrum fields in northern Tasmania, Australia were assessed in the spring and summer of 2002 (September through December) and 2003 (August through December). Different pyrethrum fields were studied in each year. In 2002, fields were situated at Burnie (UTM coordinate: $55 \mathrm{G}$ 392721 5466191) and Sisters Creek (380348 5466219), approaching their first and second harvests, respectively (Fig. 1). In 2003, fields were located at North Motton (424853 5438396) and Wesley Vale (457297 5440171), approaching their first and second harvests, respectively (Fig. 1). All fields were located within a $30-\mathrm{km}$ radius of each other. The same cultivar (proprietary) was used for each field, and each field received similar standard production practices including, irrigation, fertilizer, fungicide, and herbicide applications.

Spatial patterns of $P$. ligulicola epidemics were quantified by establishing a line transect and grid matrix in all four fields in areas that did not receive any fungicides. Disease incidence and severity measurements were performed along each transect and within each grid matrix in fields at Burnie and Sisters Creek in 2002 on 12 September, 11 October, 22 November, and 13 December. In 2003, disease assessments in the fields at North Motton and Wesley Vale were performed on 2 September, 17 October, 10 November, and 8 December. Two different sampling strategies were used to maximize the information gained from point pattern and correlation-based spatial analyses. The line transect was $10 \mathrm{~m}$ long and began at an arbitrarily selected point within an arbitrarily selected row. At $50-\mathrm{cm}$ intervals along each line transect, three flowering stems were selected on each side at $10-\mathrm{cm}$ intervals apart. On each flowering stem, defoliation incidence, defoliation severity, the incidence of stems with ray blight, and the incidence of individual flowers with ray blight were measured in situ. Defoliation severity was operationally defined as the height at which leaves were either completely necrotic or abscised (from the base of the plant) divided by the total plant height. The number of defoliated stems divided by the total number of stems (defoliation incidence) and number of flowering stems with ray

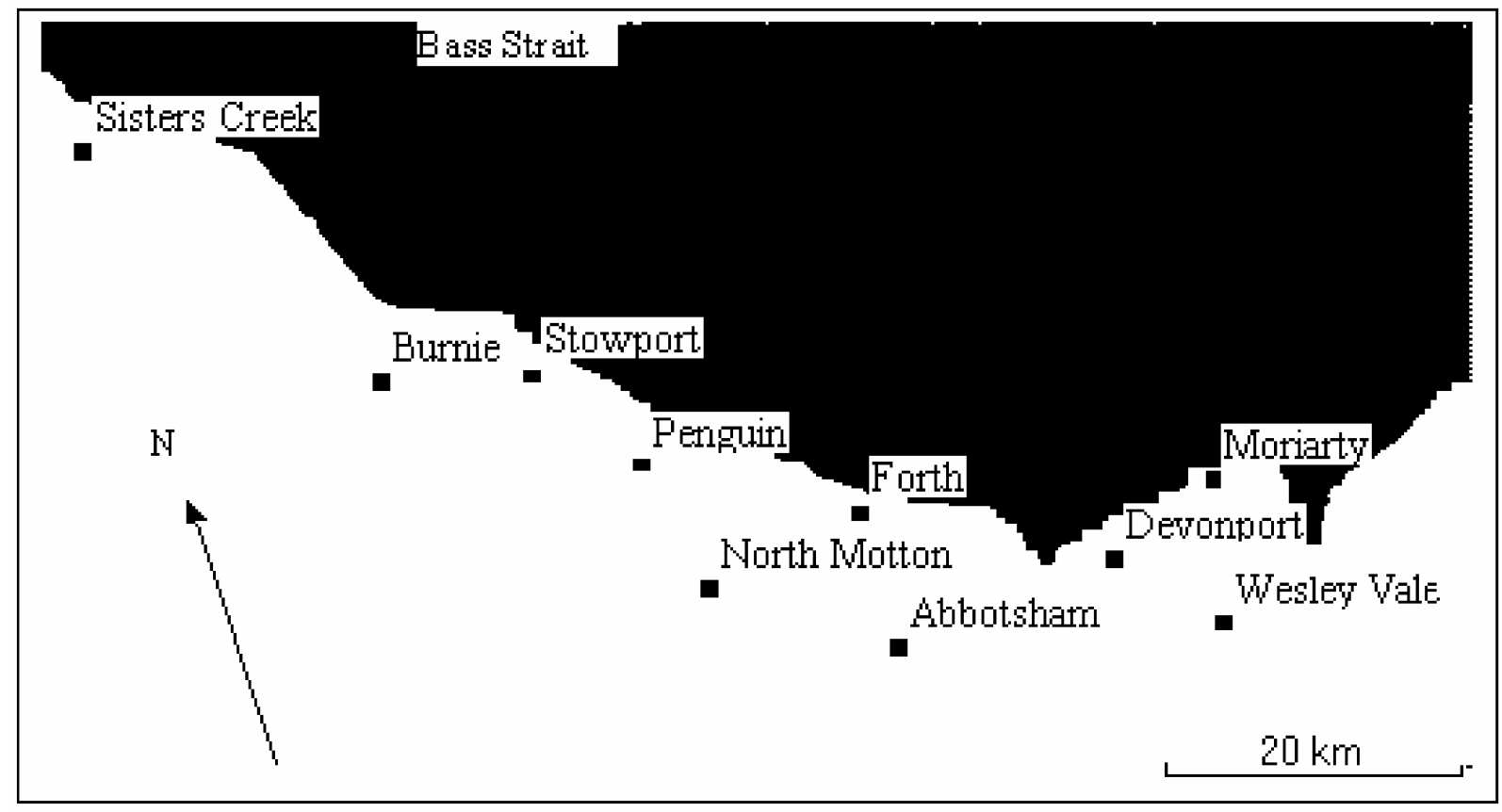

Fig. 1. Geographical position of the 10 pyrethrum fields across northern Tasmania used in this study. Fields at Burnie, Sisters Creek, North Motton, and Wesley Vale were used for spatial and spatiotemporal analysis of epidemics. Fields at Devonport, Moriarty, Stowport, Forth, Penguin, and Abbotsham were used to quantify temporal disease progress and assess the effect of fungicides. 
blight divided by the total number of flowering stems (incidence of stems with ray blight) also were quantified. The incidence of flowers with ray blight was quantified by counting the number of diseased flowers and dividing by the total number of flowers on each flowering stem.

The same disease assessments were also performed on all plants in each row within a grid matrix ( $7 \mathrm{~m}$ across by $10 \mathrm{~m}$ long) in all fields. The initial corner of each grid was selected arbitrarily within the nontreated area and three flowering stems were selected arbitrarily from each plant in 10 adjacent rows across and 20 individual plants along each row. The distance between each plant along each row and the distance between rows was measured. Disease assessment data were averaged for each plant before analyzing the spatial and spatiotemporal patterns of disease.

Point-pattern spatial analyses. The beta-binomial and binomial distributions $(15,16,23)$ were fitted to defoliation incidence and incidence of stems with ray blight data in each line transect of all fields for each assessment date using the computer program BBD (22). A good fit to the binomial distribution is suggestive of a random disease distribution, whereas an aggregated distribution is suggested by a better fit to the beta-binomial distribution. A log-likelihood ratio statistic (LRS) was used to test which distribution resulted in the best fit to the data under a null hypothesis of no significant difference between the two distributions. The index of dispersion $(D)$ also was calculated as a measure of the degree of aggregation. The index of dispersion has a $\chi^{2}$ distribution and tests for a null hypothesis of randomness with $n-$ 1 degree of freedom $(16,23)$. The index of dispersion was calculated as the ratio of the observed variance of disease incidence among the sampling units to the expected binomial variance. Values of $D>1$ suggested the presence of spatial aggregation.

Correlation-based spatial analyses. Runs analysis. Ordinary runs analysis was used to assess spatial patterns of defoliation incidence and incidence of stems with ray blight in the line transects and grid matrix assessments at each assessment date. Median runs analysis was used to characterize the spatial pattern of defoliation severity for transects and grid matrix arrangements for each assessment date in each field. Median runs analysis is an adaptation of ordinary runs analysis (24) and both analyses are special cases of cross-product statistics (21). For median runs analysis, in each data set the median level of disease severity in each transect was calculated using Microsoft Excel. Sampling units containing greater than the median were assigned a value of 1 and the remainder ( $\leq$ median) were assigned a value of 0 . For both median and ordinary runs analyses, a run was defined as a succession of like events (i.e., diseased or healthy plants) (14). Individual rows and columns were combined into a single row and column by considering the last plant of a row $(a)$ to be contiguous with the last plant of the subsequent row $(a+1)(24)$. A $Z$ statistic was used to determine whether the observed number of runs was significantly $(P \leq 0.05)$ different from the expected number of runs under the null hypothesis of randomness (24).

SADIE. The spatial distribution of defoliation incidence, defoliation severity, and incidence of stems with ray blight within the grid matrices for all fields at all assessment times were analyzed using SADIE (version 1.22). Descriptions of the theory behind SADIE have been presented previously $(30,31,47-50)$. Briefly, this technique employs a transportation algorithm to calculate the shortest distances needed to move spatially referenced data to obtain both "regular" and "crowded" spatial patterns using the same number of sampling units. These distances then are summed to calculate the overall "distance to regularity" and "distance to crowding" values. The observed and calculated distances are then compared with random simulations based on resampling of the locations of diseased measures. For all simulations, the maximum number of 5,967 randomizations was used. These distances then are used to calculate mean and percentile values to facilitate comparisons with the original data. A one-sided test for aggregation was used to assess the deviation of the index of aggregation $\left(I_{\mathrm{a}}\right)$ from the null hypothesis (i.e., no spatial dependence). The index $I_{\mathrm{a}}$ is equal to the ratio of expected and observed distances to regularity. Values $=1$ indicate a random spatial pattern, values $<1$ suggest a regular pattern, and values $>1$ suggest an aggregated pattern $(30,31)$.
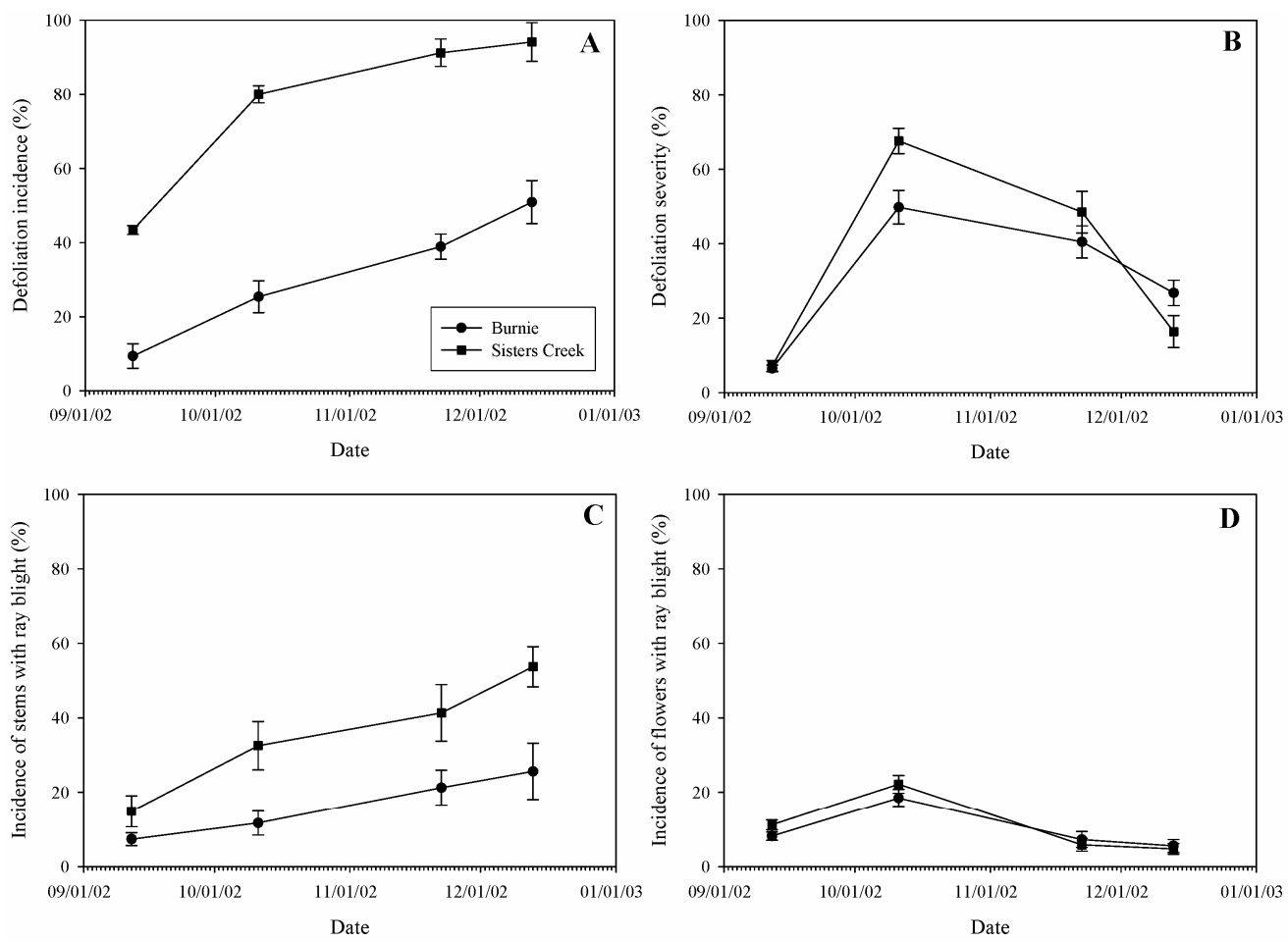

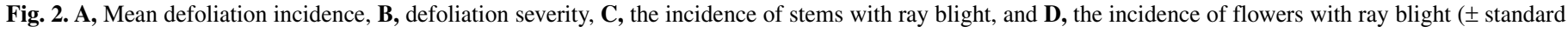

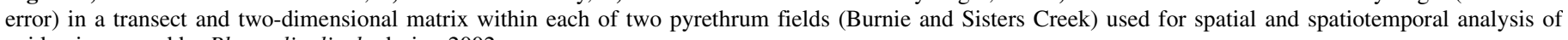
epidemics caused by Phoma ligulicola during 2002. 
Temporal analysis. Temporal disease progress was quantified in an additional six fields (Devonport, Moriarty, Stowport, Forth, Penguin, and Abbotsham) in 2003 (Fig. 1). In these fields, 60 flowering stems were systematically selected along a transect at $0.5 \mathrm{~m}$ intervals diagonal to row orientation, beginning $5 \mathrm{~m}$ away from the southeastern corner within nontreated areas $(20 \mathrm{~m}$ wide and $30 \mathrm{~m}$ in length). Disease assessments were initiated on 13 August and subsequent assessments were performed on 11 September, 24 September, 2 October, 14 October, 31 October, 18 November, and 14 December. For these assessments, individual pyrethrum stems were removed from the base of the plant and transported to the laboratory and stored at $4{ }^{\circ} \mathrm{C}$ until disease was assessed within $48 \mathrm{~h}$.

To determine which population growth model best explained disease progress with respect to time, data were fitted to the linear, monomolecular, exponential, logistic, and Gompertz models using sampling dates from 13 August to 14 October 2003 (27). After 14 October, the development of the flowering stem was too rapid for disease intensity to increase. The goodness-of-fit to the linear forms of each model were examined by comparing the $F$ statistic for linearity, the coefficient of determination $\left(R^{2}\right)$, the root mean square error, and a visual comparison of the residuals plotted against the predicted values (28). Back-transformation of the fitted disease values compared against the original disease values was performed to obtain $R^{* 2}$ values (27). Disease progress models for each location were then compared with one another using the slope (epidemic rate), $R^{* 2}$ values, the root mean square error, and the time required to reach $50 \%$ disease intensity.

Spatiotemporal analyses. Temporal associations in spatial patterns between pairs of two consecutive assessment dates were determined using the association function of SADIE (version 1.22). To test the null hypothesis of no association between spatial patterns at two consecutive assessments, association was quantified over two scales: local and overall. Local association $\left(\chi_{k}\right)$ is first measured by performing comparisons between clustering indices for each assessment time. Overall association $(X)$ then is calculated as the mean of the individual local associations. This is equivalent to calculating the correlation coefficient between the two clustering indices. Significance of $X$ was tested by randomizations with values of local association at the scale of each sampling unit, following allowance for small-scale spatial autocorrelation in the population at both time periods, referred to as the Dutilleul adjustment (11). The maximum number of 9,999 randomizations was performed and a two-tailed test was used to assess significance. For this test, a null hypothesis of no association was used (46).

Analysis of association between defoliation incidence and severity, and the incidence of stems with ray blight. Analysis of spatial association was conducted with the association function of SADIE (version 1.22), as described above for spatiotemporal associations. In this analysis, the null hypothesis assumes no association between the local spatial association (clustering indices) of the incidence and severity of defoliation, and ray blight.

Effect of fungicides on fungal foliar disease epidemics. The same disease intensity assessments also were performed in areas within the fields used to assess temporal disease progress that were treated with fungicides. Data on defoliation severity, incidence of stems with ray blight, and the incidence of ray blight within the flowers for the entire epidemic (August to December) was obtained from four evenly spaced diagonal transects within the areas not treated with fungicides and fungicide-treated areas. Fungicide treatments in each field consisted of a single Amistar (azoxystrobin) application at a rate of $300 \mathrm{~g} \mathrm{ha}^{-1}$ between 1 and 8 August, followed by Score (difenoconazole) only at $500 \mathrm{ml} \mathrm{ha}^{-1}$ between 5 and 12 September, and a final application of Score $\left(500 \mathrm{ml} \mathrm{ha}^{-1}\right)$ and Bravo 720 (chlorothalonil) at a rate of 1.4 liter $\mathrm{ha}^{-1}$ between 20 and 29 September. Each transect covered the entire length $(30 \mathrm{~m})$ of the plot and transects were separated by $5 \mathrm{~m}$. One flowering stem was collected at $0.5 \mathrm{~m}$ intervals along each transect. Transects within the areas receiving fungicides began $10 \mathrm{~m}$ away from the nontreated area. For these assessments, individual pyrethrum stems were removed at the base of
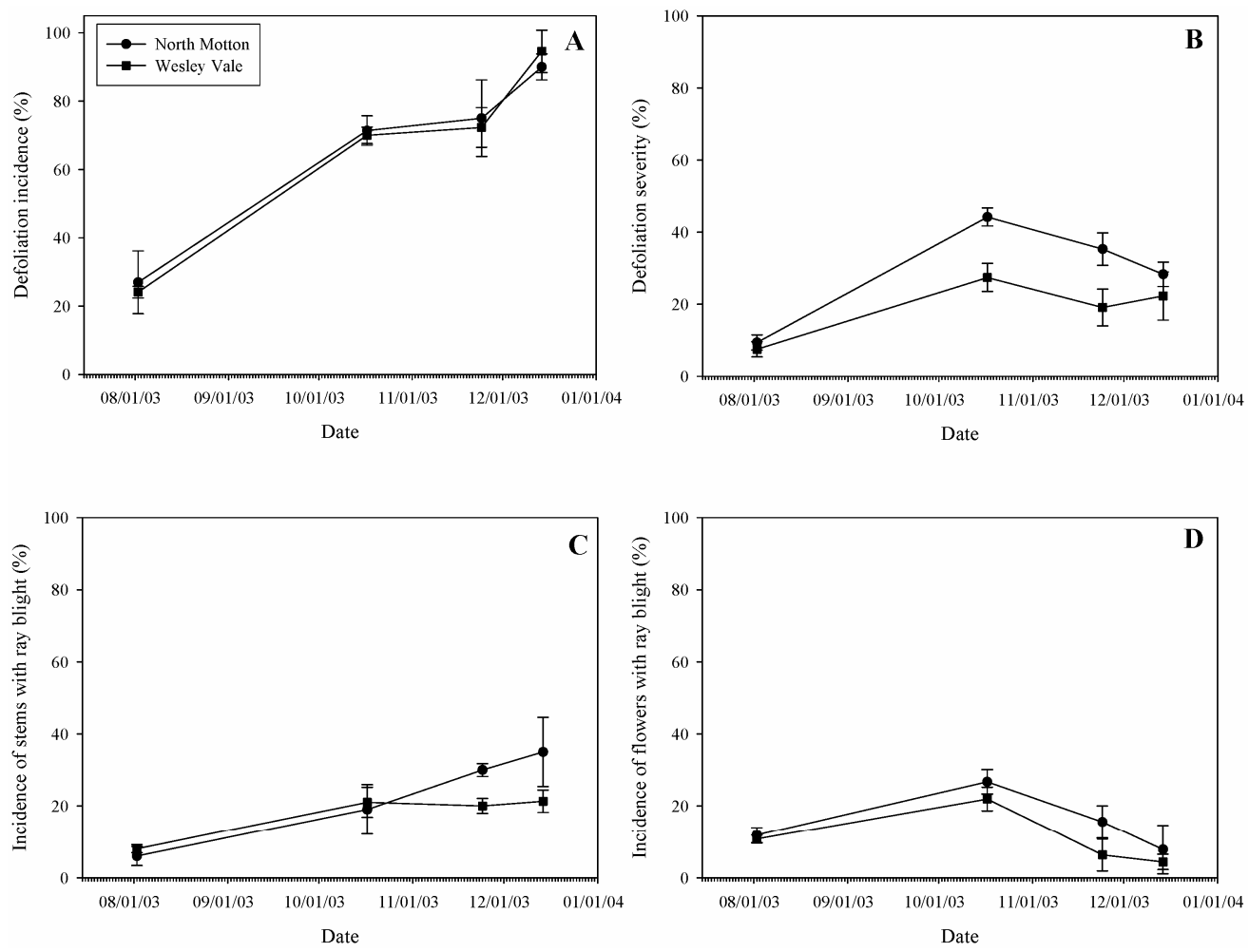

Fig. 3. A, Mean defoliation incidence, $\mathbf{B}$, defoliation severity, $\mathbf{C}$, the incidence of stems with ray blight, and $\mathbf{D}$, the incidence of flowers with ray blight ( $( \pm$ standard error) in a transect and two-dimensional matrix within each of two pyrethrum fields (North Motton and Wesley Vale) used for spatial and spatiotemporal analysis of epidemics caused by Phoma ligulicola during 2003. 
the plant (soil line), bagged, transported to the laboratory, and stored at $4^{\circ} \mathrm{C}$ until disease assessments were performed within $48 \mathrm{~h}$. Disease progress curves for the entire epidemic (August to December) for the fungicide-treated and nontreated areas within each of the six fields were used to calculate area under disease progress curves (AUDPC) (5). A mixed model analysis using the PROC MIXED procedure of SAS (SAS Institute, Cary, NC) was used to compare estimates of AUDPC in the nontreated and fungicide-treated areas, using location as a random block effect.

\section{RESULTS}

Temporal patterns in disease incidence and severity in fields used for spatial analysis. Similar temporal disease patterns were observed in both first- and second-year pyrethrum fields (Figs. 2 and 3 ). Incidence of defoliation was $\approx 10 \%$ for the first sampling in both 2002 and 2003. A linear increase in defoliation incidence was observed throughout the growing season. In all pyrethrum fields, defoliation incidence doubled between the first two assessment dates and, by the last sampling date in December, defolia- tion incidence was as high as $95 \%$. Incidence of stems with ray blight was less than the incidence of defoliation at all sampling times in both 2002 and 2003. Incidence of stems with ray blight was less than $10 \%$ on 13 August and increased linearly to $\approx 30$ to $40 \%$ by December. In 2002 , incidence of stems with ray blight was at least two times higher on all assessment dates in the first harvest field; whereas, in 2003, the incidence of stems with ray blight in the first harvest field was 1.6 times higher than in the second-year harvest field. Defoliation severity exhibited a nonlinear pattern in both 2002 and 2003 and was <10\% when assessed in September 2002 and August 2003. Disease intensity peaked in September or October in both years (40 to 60\% defoliation severity) before decreasing at the December sampling. The incidence of flowers with ray blight exhibited a similar temporal pattern to defoliation severity. Incidence of flowers with ray blight was initially $10 \%$ in both 2002 and 2003 and peaked at $\approx 20 \%$ in September 2002 and October 2003. The incidence of flowers with ray blight at the final assessment (just before harvest) was at least 1.47 times less than the first assessment in all fields.

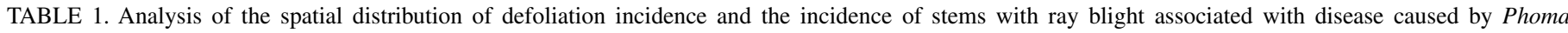

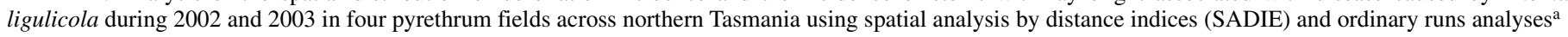

\begin{tabular}{|c|c|c|c|}
\hline \multirow[b]{2}{*}{ Field, disease measure, date } & \multirow[b]{2}{*}{$I_{\mathrm{a}}^{\mathrm{b}}$} & \multicolumn{2}{|c|}{ Ordinary runs ${ }^{\mathrm{c}}$} \\
\hline & & Across rows & Along rows \\
\hline \multicolumn{4}{|l|}{ Burnie } \\
\hline \multicolumn{4}{|l|}{ Defoliation incidence } \\
\hline 12 September 2002 & 1.17 & 1.49 & 1.49 \\
\hline 11 October 2002 & 0.76 & $-10.93 * * *$ & -0.59 \\
\hline 22 November 2002 & $1.69 * * *$ & $-9.49 * * *$ & $-3.08 * *$ \\
\hline 13 December 2002 & $1.84 * * *$ & $-11.33 * * *$ & $-5.05 * * *$ \\
\hline \multicolumn{4}{|c|}{ Incidence of stems with ray blight } \\
\hline 12 September 2002 & 0.8 & 0.93 & 0.93 \\
\hline 11 October 2002 & 1.37 & $-7.19 * * *$ & $-1.99 *$ \\
\hline 22 November 2002 & $1.29 *$ & $-10.68 * * *$ & $-6.06 * * *$ \\
\hline 13 December 2002 & 0.84 & 0.13 & 1.5 \\
\hline \multicolumn{4}{|l|}{ Sisters Creek } \\
\hline \multicolumn{4}{|l|}{ Defoliation incidence } \\
\hline 12 September 2002 & $2.21 * * *$ & $-11.52 * * *$ & $-5.29 * * *$ \\
\hline 11 October 2002 & $1.47 * *$ & $-8.69 * * *$ & $-3.53 * * *$ \\
\hline 22 November 2002 & 1.01 & $-14.63 * * *$ & $-5.59 * * *$ \\
\hline 13 December 2002 & 0.94 & $-9.57 * * *$ & $-4.08 * * *$ \\
\hline \multicolumn{4}{|c|}{ Incidence of stems with ray blight } \\
\hline 12 September 2002 & 0.87 & $-11.51 * * *$ & $-5.29 * * *$ \\
\hline 11 October 2002 & $1.61^{* *}$ & $-11.31 * * *$ & -0.83 \\
\hline 22 November 2002 & $1.48 * *$ & $-13.68 * * *$ & $-4.47 * * *$ \\
\hline 13 December 2002 & $1.37 *$ & $-15.31 * * *$ & $-4.77 * * *$ \\
\hline \multicolumn{4}{|l|}{ North Motton } \\
\hline \multicolumn{4}{|l|}{ Defoliation incidence } \\
\hline 2 August 2003 & 0.99 & 0.116 & 4.37 \\
\hline 17 October 2003 & $1.45^{* *}$ & $-11.26 * * *$ & $-9.69 * * *$ \\
\hline 24 November 2003 & $1.61 * * *$ & $-11.27 * * *$ & $-8.82 * * *$ \\
\hline 14 December 2003 & $1.98 * * *$ & $-9.44 * * *$ & $-2.52 *$ \\
\hline \multicolumn{4}{|c|}{ Incidence of stems with ray blight } \\
\hline 2 August 2003 & 1.016 & -0.91 & -0.35 \\
\hline 17 October 2003 & $1.478 * *$ & $-10.14 * * *$ & $-3.11 * *$ \\
\hline 24 November 2003 & $1.98 * * *$ & $-10.98 * * *$ & $-7.14 * * *$ \\
\hline 14 December 2003 & $1.96 * * *$ & $-10.76 * * *$ & $-6.36 * * *$ \\
\hline \multicolumn{4}{|l|}{ Wesley Vale } \\
\hline \multicolumn{4}{|l|}{ Defoliation incidence } \\
\hline 2 August 2003 & 1.01 & 2.29 & 0.39 \\
\hline 17 October 2003 & $1.84 * * *$ & $-11.82 * * *$ & $-4.36 * * *$ \\
\hline 24 November 2003 & $1.76^{* * *}$ & $-12.4 * * *$ & $-4.84 * * *$ \\
\hline 14 December 2003 & $1.91 * * *$ & $-10.38 * * *$ & $-2.52 * * *$ \\
\hline \multicolumn{4}{|c|}{ Incidence of stems with ray blight } \\
\hline 2 August 2003 & 1.02 & 1.57 & 1.57 \\
\hline 17 October 2003 & $1.88 * * *$ & $-10.04 * * *$ & $-1.9 * * *$ \\
\hline 24 November 2003 & $1.87 * * *$ & $-10.11 * * *$ & $-5.98 * * *$ \\
\hline 14 December 2003 & 1.05 & 1.24 & 1.57 \\
\hline
\end{tabular}

a Asterisks: $*, * *$, and $* * *=P<0.05,0.01$, and 0.001 , respectively.

${ }^{\mathrm{b}} I_{\mathrm{a}}$ is the index of aggregation derived from SADIE analysis.

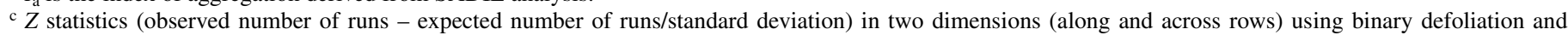
incidence of stems with ray blight data. 
Spatial analysis. In the two fields approaching their first harvests (Sisters Creek and North Motton), similar spatial patterns for all three measures of disease were obtained (Tables 1 and 2; Fig. 4). In the field at Sisters Creek, the distribution of defoliation incidence was aggregated according to ordinary runs analysis, distribution fitting, and SADIE in September and October 2002. For subsequent assessment dates, the spatial distribution was ran-

TABLE 2. Analysis of the spatial distribution of defoliation severity associated with disease caused by Phoma ligulicola during 2002 and 2003 in four pyrethrum fields across northern Tasmania using spatial analysis by distance indices (SADIE) and median runs analyses ${ }^{\mathrm{a}}$

\begin{tabular}{|c|c|c|c|}
\hline \multirow[b]{2}{*}{ Field, date } & \multirow[b]{2}{*}{$I_{\mathrm{a}}^{\mathrm{b}}$} & \multicolumn{2}{|c|}{ Median runs ${ }^{\mathrm{c}}$} \\
\hline & & Across rows & Along rows \\
\hline \multicolumn{4}{|l|}{ Burnie } \\
\hline 12 September 2002 & 1.04 & 1.13 & 1.13 \\
\hline 11 October 2002 & 0.39 & $-10.33^{* * *}$ & -1.09 \\
\hline 22 November 2002 & $1.73^{* * *}$ & $-8.66 * * *$ & $-4.10^{* *}$ \\
\hline 13 December 2002 & $1.81 * * *$ & $-10.65 * * *$ & $-6.47 * * *$ \\
\hline \multicolumn{4}{|l|}{ Sisters Creek } \\
\hline 12 September 2002 & $1.97 * * *$ & $-10.16 * * *$ & $-3.91 * * *$ \\
\hline 11 October 2002 & $1.78^{* * * *}$ & $-10.02 * * *$ & $-5.18 * * *$ \\
\hline 22 November 2002 & $2.02 * * *$ & $-14.33^{* * * *}$ & $-7.68 * * *$ \\
\hline 13 December 2002 & $1.95 * * *$ & $-12.93 * * *$ & $-8.64 * * *$ \\
\hline \multicolumn{4}{|l|}{ North Motton } \\
\hline 2 August 2003 & 0.99 & $-3.97 * *$ & -0.58 \\
\hline 17 October 2003 & $1.46 * *$ & $-8.67 * * *$ & $-6.49 * * *$ \\
\hline 24 November 2003 & $1.87 * * *$ & $-10.82 * * *$ & $-7.63 * * *$ \\
\hline 14 December 2003 & $2.01 * * *$ & $-9.99 * * *$ & $-7.59 * * *$ \\
\hline \multicolumn{4}{|l|}{ Wesley Vale } \\
\hline 2 August 2003 & 1.11 & $-2.22 * *$ & $-4.76 * *$ \\
\hline 17 October 2003 & $1.94 * * *$ & $-8.99 * * *$ & $-1.72 * * *$ \\
\hline 24 November 2003 & $1.96 * * *$ & $-11.38 * * *$ & $-7.32 * * *$ \\
\hline 14 December 2003 & $2.01 * * *$ & $-8.52 * * *$ & $-9.86 * * *$ \\
\hline
\end{tabular}

a Asterisks: *, **, and $* * *=P<0.05,0.01$, and 0.001 , respectively.

${ }^{\mathrm{b}} I_{\mathrm{a}}$ is the index of aggregation derived from SADIE analysis.

${ }^{c} Z$ statistics (observed number of runs - expected number of runs/standard deviation) in two dimensions (along and across rows) after median run conversion for severity data. dom by SADIE, but aggregated in both directions by ordinary runs analysis. Severity of defoliation was aggregated on scales both above and below the sampling unit for all assessments. Incidence of stems with ray blight was found to be random only on 12 September, when crop growth was rapid, based on SADIE, while ordinary runs analysis indicated a significant $(P<0.001)$ aggregation in both directions. Results from distribution fitting of binary data (defoliation and incidence of stems with ray blight) agreed with ordinary runs analyses in all situations. At North Motton, the spatial distribution of defoliation incidence and incidence of stems with ray blight were random on 2 August 2003, but subsequently aggregated based on SADIE, distribution fitting (Fig. 4 ), and ordinary runs analyses in both directions. Defoliation severity was aggregated after 17 October 2003 based on SADIE and median runs analyses, except on 2 August, when defoliation severity was random using SADIE but significantly aggregated only across rows using median runs analyses (Tables 1 and 2).

In the fields approaching their second-year harvest (Burnie and Wesley Vale), defoliation incidence was random on 12 September 2002 and aggregated on 22 November and 13 December, based on SADIE, distribution fitting (Fig. 4), and ordinary runs analysis. However, on 11 October, the distribution of defoliation incidence was random based on SADIE as well as along rows using ordinary runs analysis. Across rows, however, the pattern was aggregated. Spatial patterns for defoliation severity followed a similar pattern as with defoliation incidence. For example, both SADIE and median runs analyses suggested a random distribution on 12 September and an aggregated distribution at the latter two assessment dates, but a random distribution was found on 11 October based on SADIE. However, a significant anisotropic distribution of aggregation across rows was found, suggesting that aggregation was not significant enough in all directions to be detected by SADIE. For the incidence of stems with ray blight, a random distribution was suggested by SADIE, distribution fitting (Fig. 4), and ordinary runs analyses for the first and last assessment dates, whereas an aggregated distribution was found on 22 November. In the field at Wesley Vale, defoliation incidence was random on 2
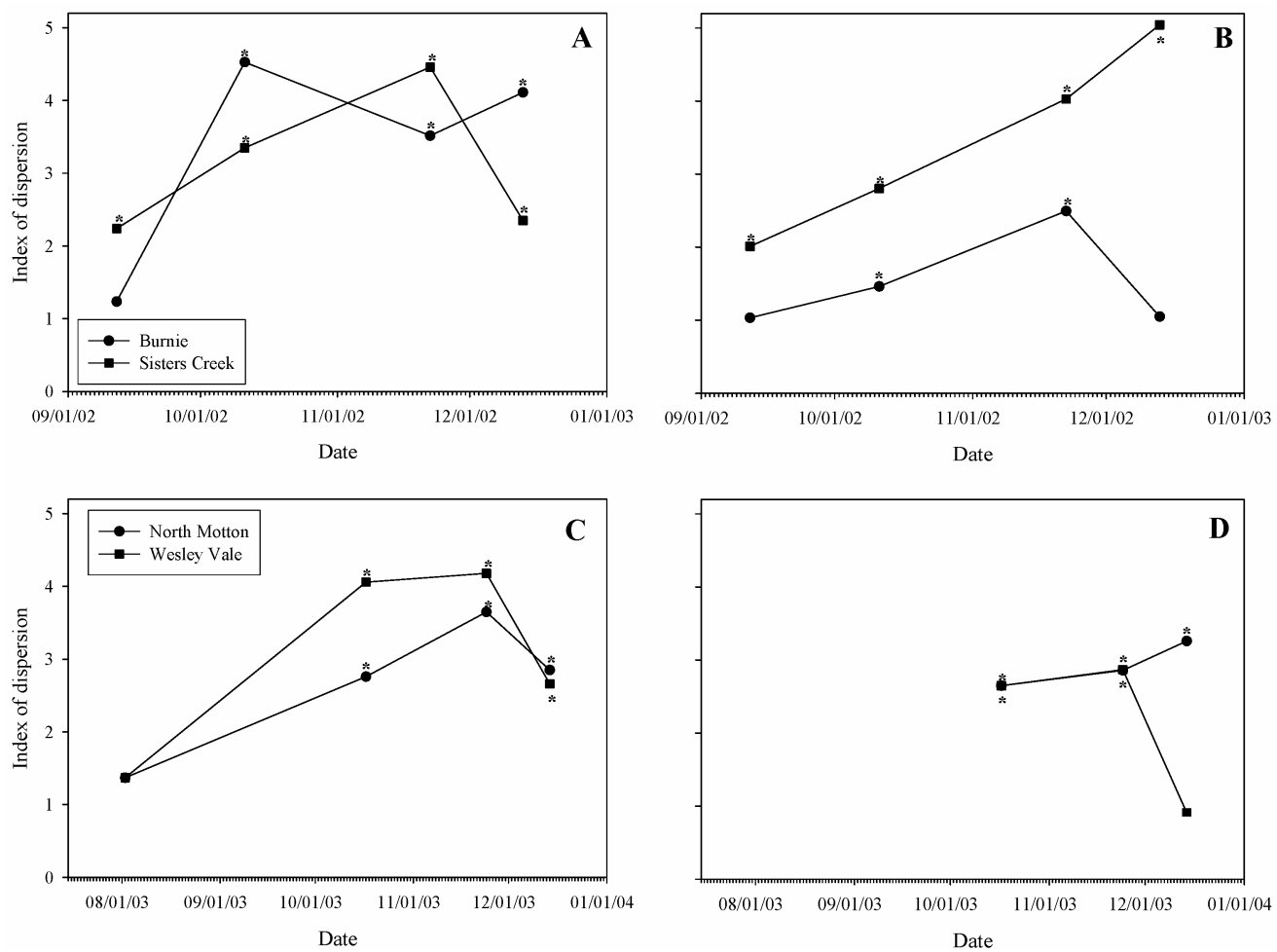

Fig. 4. A, Index of dispersion calculated by fitting the beta-binomial and binomial distributions for defoliation incidence and $\mathbf{B}$, the incidence of stems with ray blight in 2002, and $\mathbf{C}$, defoliation incidence and $\mathbf{D}$, the incidence of stems with ray blight in 2003. Asterisks indicate $P<0.001$. 
August 2003 and aggregated by all spatial techniques for assessments performed from October to December. Defoliation severity also was aggregated according to all spatial techniques for the last three assessments. On 2 August, a random distribution was suggested by SADIE, whereas an aggregated distribution in both directions was detected by median runs analyses. For the incidence of stems with ray blight, a random distribution was suggested by all spatial techniques on the first and last assessment dates; whereas, on 17 October and 24 November, all spatial techniques depicted an aggregated distribution (Tables 1 and 2).
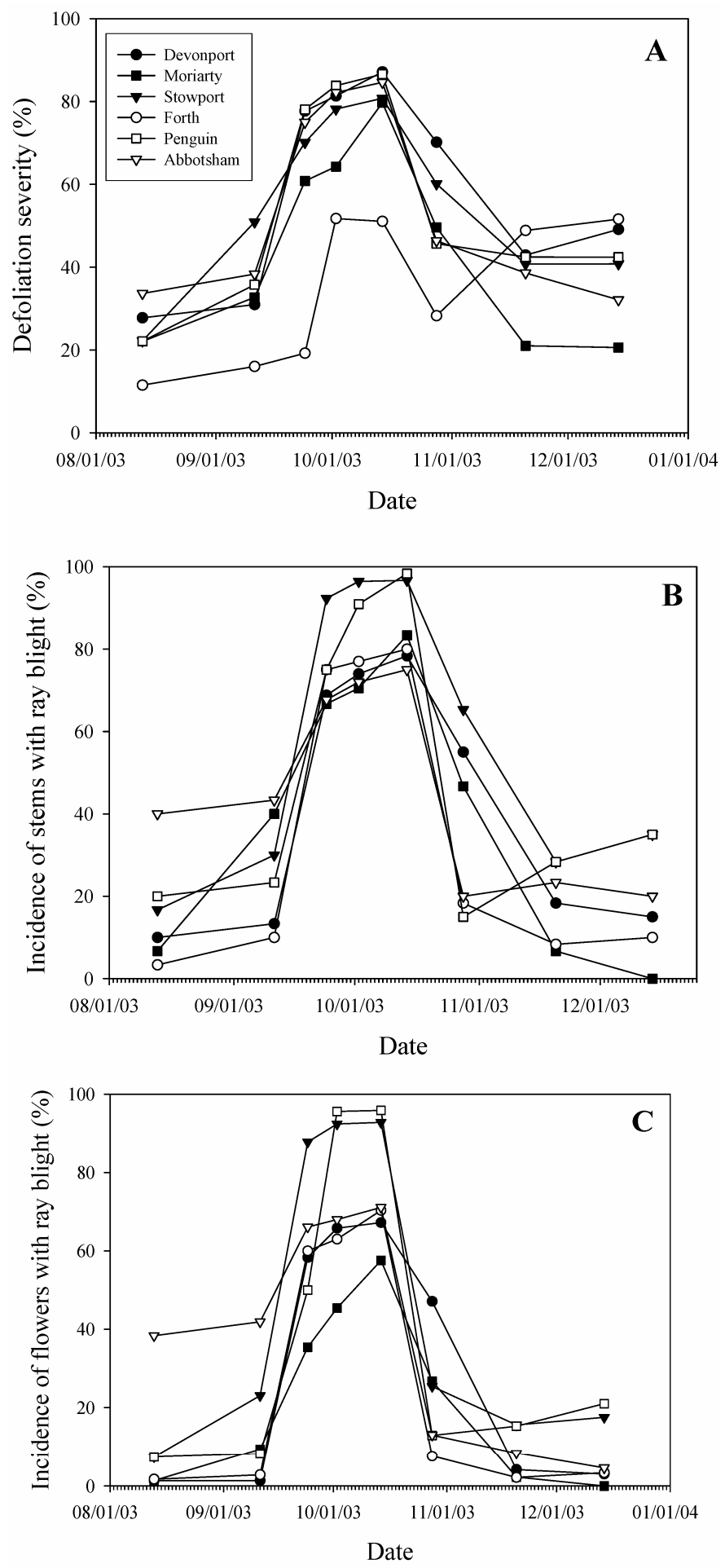

Fig. 5. A, Mean defoliation severity, $\mathbf{B}$, the incidence of stems with ray blight, and $\mathbf{C}$, the incidence of flowers with ray blight in nontreated areas from 13 August to 14 December in six pyrethrum fields across northern Tasmania in 2003.
Modeling temporal disease progress. Among the six fields on the 13 August, defoliation severity ranged from 11.5 to $33.6 \%$, the incidence of ray blight ranged from 3.3 to $40 \%$, and the incidence of flowers with ray blight from 1.3 to $40 \%$ (Figs. 5 and 6). Defoliation severity was best described by the logistic model for all six pyrethrum fields (Fig. 5; Table 3). Based on the logistic model, 76.6 to $98.6 \%$ of the variation in logit defoliation severity $\left(R^{* 2}\right)$ was explained by time. Despite differences in initial inoculum (Fig. 5), the rate of defoliation severity generally was slow to moderate ( 0.036 and 0.056 logits per day among the six fields). Both the incidence of stems with ray blight and the incidence of flowers with ray blight over time were best described by either the logistic or Gompertz models. For the incidence of stems with ray blight, the Gompertz model provided the best fit in fields at Devonport and Moriarty, explaining between 76.7 and $98.9 \%$ of the variation in incidence of stems with ray blight. In fields at Stowport, Forth, Penguin, and Abbotsham, the logistic model provided the best fit, explaining 79.1 to $86.2 \%$ of the variation in the incidence of stems with ray blight. For the incidence of flowers with ray blight, 83.2 to $89.2 \%$ of the variation was explained by time within fields at Stowport, Penguin, and Abbotsham based on the logistic model. In the other three fields, the Gompertz model best fit the disease progress data, explaining 85 to $97 \%$ of the variation in the incidence of flowers with ray blight (Table 3 ).

Differences were observed among the locations in both the number of days required to reach $50 \%$ disease intensity, maximum disease intensity observed on 14 October, and final disease intensity on the last assessment date on 14 December 2003. Days to $50 \%$ defoliation severity ranged from 20 (Abbotsham) to 66 (Forth). The number of days required to reach $50 \%$ for the incidence of stems with ray blight ranged from 21 (Abbotsham) to 40
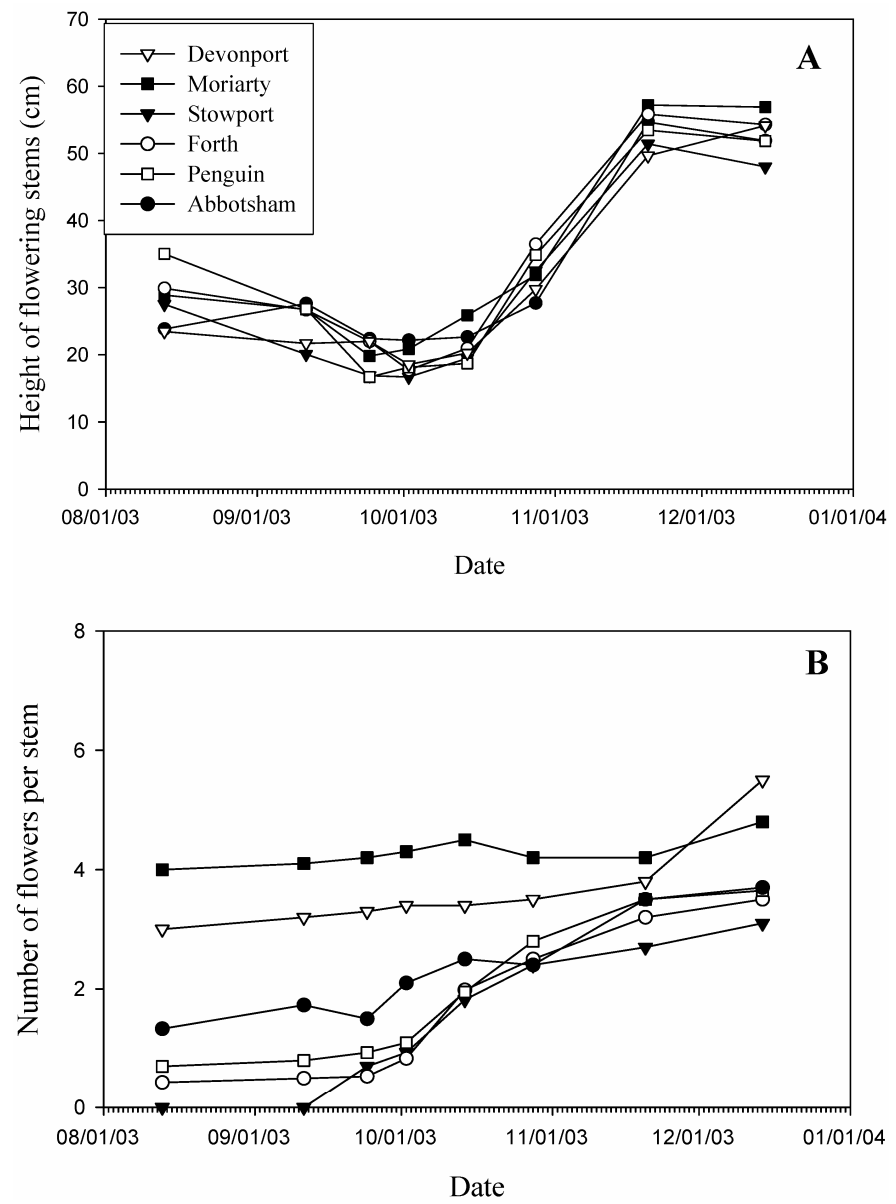

Fig. 6. A, Mean height of flowering stems and B, number of flowers on each flowering stem in nontreated areas from 13 August to 14 December in six pyrethrum fields across northern Tasmania in 2003. 
(Forth). The time to reach $50 \%$ of flowers with ray blight also was shortest for the field at Abbotsham (26 days), whereas it took 55 days at Moriarty (Fig. 5; Table 3).

Spatiotemporal analyses. Significant spatial associations $(P<$ $0.001)$ were detected for all the clustering indices of defoliation incidence and severity for all successive assessment times in all fields in both seasons (Table 4). The clustering indices of the incidence of stems with ray blight also were associated strongly $(P<$ 0.001 ) between all successive assessment times in both fields approaching their first harvest. This also was the case in the majority of analyses conducted for fields approaching their second-year harvest; however, no significant spatial associations were detected

TABLE 3. Model of best fit to temporal disease progress from 13 August to 14 October 2003 selected by comparison with linearized forms of the linear, monomolecular, exponential, logistic, and Gompertz models and the use of back-transformation statistics for comparison between models in six pyrethrum fields across northern Tasmania

\begin{tabular}{|c|c|c|c|c|c|c|c|c|}
\hline \multirow[b]{2}{*}{ Disease measure, field } & \multirow[b]{2}{*}{ Best fit ${ }^{\mathrm{a}}$} & \multirow[b]{2}{*}{ Slope } & \multirow[b]{2}{*}{ Intercept } & \multirow[b]{2}{*}{$R^{* 2 \mathrm{~b}}$} & \multirow[b]{2}{*}{$\mathrm{RMSE}^{\mathrm{c}}$} & \multirow[b]{2}{*}{ Days to $50 \%$ d } & \multicolumn{2}{|c|}{ Disease on } \\
\hline & & & & & & & 14 Oct 2003 & 14 Dec 2003 \\
\hline \multicolumn{9}{|l|}{ Defoliation severity } \\
\hline Devonport & Logistic & 0.052 & -12.924 & 0.805 & 0.1316 & 24 & 87.1 & 49.1 \\
\hline Stowport & Logistic & 0.046 & -11.590 & 0.986 & 0.0322 & 27 & 80.8 & 40.8 \\
\hline Forth & Logistic & 0.036 & -10.483 & 0.766 & 0.0834 & 66 & 51.1 & 51.6 \\
\hline Penguin & Logistic & 0.056 & -14.144 & 0.886 & 0.1068 & 28 & 86.6 & 42.4 \\
\hline Devonport & Gompertz & 0.041 & -10.410 & 0.767 & 0.1657 & 38 & 78.3 & 15.0 \\
\hline Moriarty & Gompertz & 0.044 & -10.824 & 0.989 & 0.0354 & 29 & 83.3 & 0 \\
\hline Stowport & Logistic & 0.093 & -22.892 & 0.803 & 0.1811 & 21 & 96.7 & 35.0 \\
\hline Forth & Logistic & 0.088 & -23.299 & 0.862 & 0.1432 & 40 & 80 & 10.0 \\
\hline Penguin & Logistic & 0.089 & -22.221 & 0.791 & 0.1864 & 25 & 98.3 & 35.0 \\
\hline Abbotsham & Logistic & 0.027 & -6.719 & 0.831 & 0.0721 & 24 & 75 & 20 \\
\hline \multicolumn{9}{|c|}{ Incidence of flowers with ray blight } \\
\hline Abbotsham & Logistic & 0.025 & -6.263 & 0.832 & 0.0672 & 26 & 71.1 & 4.5 \\
\hline
\end{tabular}

${ }^{a}$ Model of best fit selected by fitting the linear, monomolecular, exponential, logistic, and Gompertz models using nonlinear regression from 13 August to 14 October 2003, and examination of the linear forms of each model by comparing the $F$ statistic for linearity, the coefficient of determination $\left(R^{* 2}\right)$, the standard error for the estimate of $Y$, and a visual comparison of the residuals plotted versus $x$. Further selection was made by back-transforming the data and comparing the new $R^{* 2}$ values.

${ }^{\mathrm{b}}$ Back-transformed $R^{* 2}$.

${ }^{c}$ Root mean square error.

d Number of days to $50 \%$ disease.

TABLE 4. Spatiotemporal analysis of defoliation incidence and severity and the incidence of stems with ray blight associated with disease caused by Phoma ligulicola in four pyrethrum fields across northern Tasmania in 2002 and 2003

\begin{tabular}{|c|c|c|c|c|c|c|c|c|}
\hline \multirow[b]{2}{*}{ Disease measure } & \multicolumn{2}{|c|}{ Assessment dates 2002} & \multicolumn{2}{|c|}{ Overall association $(X)^{\mathrm{a}}$} & \multicolumn{2}{|c|}{ Assessment dates 2003} & \multicolumn{2}{|c|}{ Overall association $(X)^{\mathrm{a}}$} \\
\hline & 1 & 2 & Burnie & Sisters Creek & 1 & 2 & North Motton & Wesley Vale \\
\hline \multirow[t]{2}{*}{ Def. incidence } & $12 \mathrm{Sept}$ & 11 Oct & $0.565 * * *$ & $0.414 * * *$ & 2 Aug & 17 Oct & $0.465 * * *$ & $0.413 * * *$ \\
\hline & 11 Oct & $22 \mathrm{Nov}$ & $0.432 * * *$ & $0.767 * * *$ & 17 Oct & $24 \mathrm{Nov}$ & $0.654 * * *$ & $0.518 * * *$ \\
\hline \multirow[t]{3}{*}{ Def. severity } & $12 \mathrm{Sept}$ & $11 \mathrm{Oct}$ & $0.539 * * *$ & $0.527 * * *$ & 2 Aug & 17 Oct & $0.678 * * *$ & $0.567 * * *$ \\
\hline & $11 \mathrm{Oct}$ & $22 \mathrm{Nov}$ & $0.244 * * *$ & $0.753 * * *$ & 17 Oct & $24 \mathrm{Nov}$ & $0.453 * * *$ & $0.526 * * *$ \\
\hline & $22 \mathrm{Nov}$ & $13 \mathrm{Dec}$ & $0.816^{* *}$ & $0.816^{* * *}$ & $24 \mathrm{Nov}$ & $14 \mathrm{Dec}$ & $0.854 * * *$ & $0.823 * * *$ \\
\hline
\end{tabular}

${ }^{a}$ Overall association $(X)$. Two-tail test significance levels of $P<0.05, P<0.01$, and $P<0.001$ are indicated by *, **, and $* * *$, respectively.

TABLE 5. Analysis of association between either defoliation incidence or severity and the incidence of stems with ray blight associated with disease caused by Phoma ligulicola in four pyrethrum fields across northern Tasmania on assessment dates in 2002 and 2003

\begin{tabular}{|c|c|c|c|c|c|c|}
\hline \multirow[b]{2}{*}{ Defoliation } & \multirow[b]{2}{*}{2002} & \multicolumn{2}{|c|}{ Overall association $(X)^{\mathrm{a}}$} & \multirow[b]{2}{*}{2003} & \multicolumn{2}{|c|}{ Overall association $(X)^{\mathrm{a}}$} \\
\hline & & Burnie & Sisters Creek & & North Motton & Wesley Vale \\
\hline \multirow{2}{*}{ Incidence } & 12 September & 0.057 & $0.419 * * *$ & 2 August & $0.521 * * *$ & 0.061 \\
\hline & 13 December & 0.065 & $0.344 * * *$ & 14 December & $0.359 * * *$ & 0.046 \\
\hline \multirow[t]{2}{*}{ Severity } & 12 September & 0.043 & $0.469 * * *$ & 2 August & $0.651 * * *$ & 0.039 \\
\hline & 11 October & -0.071 & $0.667 * * *$ & 17 October & $0.514 * * *$ & 0.021 \\
\hline
\end{tabular}

a Overall association $(X)$. Two-tail test significance levels of $P<0.01$ and $P<0.001$ are indicated by ** and ***, respectively. 
between the third and fourth assessment dates in fields at Burnie and Wesley Vale (Table 4).

Analysis of association between defoliation incidence and severity and incidence of stems with ray blight. Significant spatial associations $(P<0.001)$ were detected between defoliation severity and incidence of stems with ray blight, and defoliation incidence and incidence of stems with ray blight at all assessments in fields approaching their first year harvest in both seasons (Table 5). In the fields at Burnie and Wesley Vale, no significant
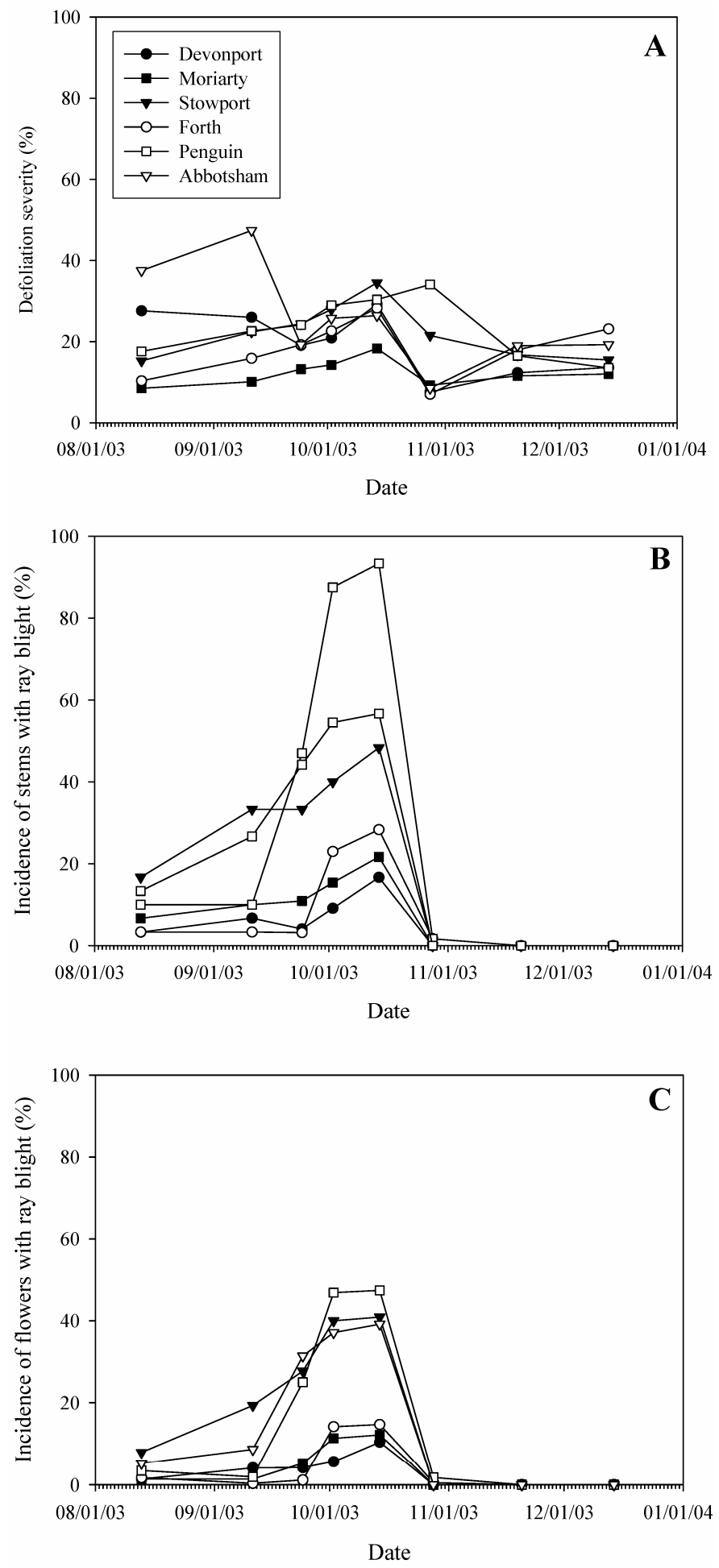

Fig. 7. A, Mean defoliation severity, $\mathbf{B}$, the incidence of stems with ray blight, and $\mathbf{C}$, the incidence of flowers with ray blight within areas receiving fungicides from 13 August to 14 October in six pyrethrum fields across northern Tasmania in 2003. associations between defoliation severity or incidence and incidence of stems with ray blight were detected for the first two assessment dates or for the final assessment date (Table 5).

Effect of fungicides on foliar disease epidemics. Temporal rates of disease progress in fungicide-treated pyrethrum were reduced significantly compared with the disease rates in the nontreated pyrethrum (Figs. 5 and 7). Significantly lower $(P<$ 0.001) AUDPC values were obtained for defoliation severity, the incidence of stems with ray blight, and the incidence of flowers with ray blight in the fungicide-treated section of the fields (Table 6).

\section{DISCUSSION}

The results from this research have provided new quantitative information concerning the epidemiology and management of $P$. ligulicola in Tasmanian pyrethrum fields. Based on the rapid increase in disease intensity between August and September, this is most likely the critical infection period for pyrethrum due to $P$. ligulicola, and hence when management strategies should be targeted. Temporal analyses of P. ligulicola epidemics in the nontreated areas of six pyrethrum fields indicated a slow-to-moderate increase in disease intensity over a 10 -week period (until midOctober) based on the finding that infection rates ranged from 0.025 to 0.103 logits/day or 0.035 to 0.046 gompits/day for the various assessment methods. After mid-October, flowering stem growth exceeded the rate of disease development and, hence, disease did not increase after this date (Figs. 5 and 6). After midOctober, disease intensity decreased in an exponential fashion as the crop approached harvest in December. When examining disease progress from early August to mid-October, the logistic model best described the change in defoliation severity with respect to time for all six field locations, whereas the incidence of stems with ray blight and the incidence of flowers with ray blight were best described by either the Gompertz or logistic models. Both the logistic and Gompertz models describe polycyclic diseases, in which there are multiple disease cycles within a growing season $(5,21)$. Among pyrethrum fields, the rate of disease development as measured by the days to $50 \%$ incidence and severity assessments differed greatly. For defoliation severity, there was a threefold difference between fields at Forth and Abbotsham on 14 December. A similar disease intensity pattern also was observed for the incidence of stems with ray blight and incidence of flowers with ray blight. Disease progress was more rapid at fields at Stowport, Penguin, and Abbotsham, which may indicate a higher risk of disease at particular sites (28), suggesting that site-specific risk factors (e.g., microclimate or site edaphic factors) may affect disease development.

Fungicides reduced crop injury (i.e., reduced disease intensity over the entire growing season) caused by $P$. ligulicola epidemics in 2003. Reducing the rate may lessen the influence of $P$. ligulicola on crop development, resulting in higher yields (S. J. Pethybridge, unpublished data). Prior studies have attributed this critical period to an increase in the number of consecutive days with rain $>0.1 \mathrm{~mm}(34,35)$. Implementing disease management strategies during this period may not only slow the rate of disease development but also improve plant development as demonstrated

TABLE 6. Mean values for the $\mid A U D P C_{\text {treated }}-\mathrm{AUDPC}_{\text {control }}$ for defoliation severity, incidence of stems with ray blight, and the incidence of flowers with ray blight obtained at six pyrethrum fields across northern Tasmania, Australia $^{\mathrm{a}}$

\begin{tabular}{lccc}
\hline Disease measure & Mean & $t$ value & $P$ \\
\hline Defoliation severity & $3,364.5$ & -8.08 & $<0.0001$ \\
Incidence of stems with ray blight & $3,175.8$ & -6.96 & $<0.0001$ \\
Incidence of flowers with ray blight & $2,502.4$ & -7.31 & $<0.0001$ \\
\hline
\end{tabular}

a AUDPC $=$ area under the disease progress curve. 
by less defoliation and higher numbers of secondary and tertiary stems, which lead to flowers (Fig. 6A). The average number of flowers on flowering stems also reached a peak following midOctober (Fig. 6B).

In first-year harvest fields, the random distribution of disease early in the season may be due to different modes of pathogen entry into the field, including (most likely) the occurrence of diseased seedlings that developed from infected seed (S. J. Pethybridge, unpublished data) or windblown ascospores of the teleomorph, D. ligulicola (3). Ascospores ejected from ascocarps during autumn and winter during damp weather have been suggested as a primary source of inoculum in chrysanthemum crops (12); however, the dissemination of ascospores originating from neighboring older pyrethrum fields to newly emerged pyrethrum fields should result in an obvious disease gradient (aggregated spatial pattern) due to size, shape, and terminal velocity characteristics of ascospores that would limit dispersal distances. However, if the source of ascospores is distant, then the resulting disease is likely to be randomly distributed over the field. Thereafter, $P$. ligulicola epidemics become aggregated as foci develop and expand over time due to rain-splashed conidia (2). Moreover, the significant associations among the different disease intensity assessment methods suggest that a local (within-field) source of inoculum may be a significant factor for the ray blight phase of this disease. Local within-field sources of inoculum are also suggested as being important for defoliation severity as observed by aggregation of diseased plants late in the season and the consistent demonstration of significant spatiotemporal associations between successive time periods for the different disease intensity measures. This also is supported by the significant association observed between defoliation severity and the incidence of stems with ray blight at all sampling times in fields approaching their first harvest. Pycnidia production in chrysanthemum has been related to periods of high moisture (19), such as those that occur in August to mid-October in Tasmania (35). Furthermore, pycnidia production is extremely rapid, being produced in 3-day-old lesions under optimal temperatures of $26^{\circ} \mathrm{C}(19)$.

In the two fields approaching their second-year harvest, the spatial patterns of defoliation incidence and severity were similar to those observed in first-harvest fields late in the growing season. However, ray blight incidence (both stems and flowers) was found to be initially random, as opposed to defoliation severity assessments, which initially were aggregated. Incidence of stems with ray blight then was aggregated during the production season, but again was random as harvest approached. Spatiotemporal analysis clearly demonstrated that defoliation incidence and severity in all field locations and years were strongly associated between two successive assessment times, because the spatial distribution of foliar disease intensity assessed at time $t$ was similar to the previous assessment time $(t-1)$. A significant spatiotemporal association for incidence of stems with ray blight also followed a similar association pattern for the majority of $P$. ligulicola epidemics in both first- and second-harvest crops. This suggested that the spatial pattern of diseases at subsequent time periods were associated, thus suggesting the expansion of existing foci. However, the incidence of stems with ray blight in fields approaching their second-year harvest was not spatiotemporally associated between successive disease assessment dates in November and December. This, along with the random distribution of incidence of stems with ray blight in December, suggests that external sources of inoculum may be the source of inoculum for flowers in older fields due to windblown ascospores in the month preceding harvest $(2,38,45)$. This time period (December) coincides with the onset of drier summer conditions in Tasmania (35), yet flower infection continues to increase. Studies of chrysanthemum ray blight have suggested that perithecia development is accelerated under dry conditions in lesions at least 7 days old (19). McCoy and Dimock (18) demonstrated that ascospore liberation could oc- cur with only $0.1 \mathrm{~mm}$ of moisture accumulation. Pyrethrum fields in Tasmania are irrigated in summer at 7-day intervals using overhead irrigation; therefore, this source of moisture could provide favorable conditions for ascospore and conidia liberation and infection. The role of external ascospores in fields approaching their second year of harvest is further suggested by the absence of an association between defoliation incidence and severity with the incidence of stems with ray blight in the second harvest. This suggests that, in older pyrethrum fields, defoliation may not be influencing flower infection. However, more research is necessary to determine the stimulus-response relationships among these different diseased tissues. Prior studies on chrysanthemum ray blight have shown that the production of perithecia on mature chrysanthemum tissue coincides with the production of the most susceptible host tissue, the buds and flowers (18). McCoy and Dimock (18) also concluded that ascospore infection plays an important role in causing disease in the flowers.

Reducing the loss of healthy green tissue due to P. ligulicola is essential for effective disease management and for minimizing yield losses. However, more work is needed to reduce the number and improve the timing of fungicide applications, especially if there is an external source of ascospores throughout the growing season that can infect developing flowers after the efficacy of previous fungicide applications have ceased. The absence of a significant relationship between defoliation incidence and severity and incidence of stems with ray blight prior to harvest in December indicates that this may be a concern, and relying solely on reducing the loss of green leaf tissue does not provide sufficient protection to completely reduce flower infections (i.e., crop loss). If external sources of inoculum continue to drive the epidemic at this stage, the relative cost and benefits from additional fungicides applied up to harvest needs to be investigated.

We have been able to determine the probable source of pathogen inoculum and factors that may influence management decisions concerning overhead irrigation and fungicide use. Future research will aim at identifying the presence of the teleomorph, because it is clear that this stage of the pathogen lifecycle may have a substantial role in the epidemiology of this pathosystem. Determining the teleomorph's role in population genetics and its influence on developing future disease management programs will also be important. Additional studies late in the production season are needed to better understand late-season disease dynamics. Incorporation of our findings into the MYCOS model that was developed for chrysanthemum ray blight has the potential to lead to a disease warning model that will be more applicable to Tasmania $(18,19)$.

\section{ACKNOWLEDGMENTS}

This project was supported by funds from the Australian Research Council-Linkage program and Botanical Resources Australia Pty, Ltd. We thank J. Scott, CSIRO-Brisbane and M. Gleason, Iowa State University, for their constructive comments.

\section{LITERATURE CITED}

1. Baker, K. F., and Davis, L. H. 1959. Ascochyta disease of chrysanthemum appears in California. Calif. State Florists Assoc. Mag. 8:A-B.

2. Baker, K. F., Dimock, A. W., and Davis, L. H. 1949. Life history and control of the Ascochyta ray blight of chrysanthemum. Phytopathology 39:789-805.

3. Baker, K. F., Dimock, A. W., and Davis, L. H. 1961. Cause and prevention of the rapid spread of the Ascochyta disease of chrysanthemum. Phytopathology 51:96-101.

4. Blakeman, J. P., and Hornby, D. 1966. The persistence of Colletotrichum coccoides and Mycosphaerella ligulicola in soil, with special reference to sclerotia and conidia. Trans. Br. Mycol. Soc. 49:227-240.

5. Campbell, C. L., and Madden, L. V. 1990. Introduction to Plant Disease Epidemiology. John Wiley \& Sons, New York.

6. Casida, J. E., and Quistad, G. B. 1995. Pyrethrum Flowers: Production, Chemistry, Toxicology and Uses. Oxford University Press, New York. 
7. Chesters, C. G. C., and Blakeman, J. P. 1966. The survival on chrysanthemum roots of epiphytic mycelium of Mycosphaerella ligulicola. Ann. Appl. Biol. 58:291-298.

8. Chesters, C. G. C., and Blakeman, J. P. 1967. Host range and variation in virulence of Mycosphaerella ligulicola. Ann. Appl. Biol. 60:385-390.

9. Cliff, A. D., and Ord, J. K. 1981. Spatial Processes: Models and Applications. Pion Ltd., London.

10. Cressie, N. 1991. Statistics for Spatial Data. John Wiley \& Sons, New York.

11. Dutilleul, P. 1993. Modifying the $t$-test for assessing the correlation between two spatial processes. Biometrics 49:305-314.

12. Fox, R. T. V. 1998. Chrysanthemum ray blight. Mycologist 12:135-136.

13. Gibbons, J. D. 1985. Nonparametric Methods for Quantitative Analysis. 2nd ed. American Sciences Press, Columbus, OH.

14. Habili, N., and Nutter, F. W., Jr. 1997. Temporal and spatial analysis of grapevine leafroll-associated virus 3 in Pinot Noir grapevines in Australia. Plant Dis. 81:625-628.

15. Hughes, G., and Madden, L. V. 1992. Aggregation and incidence of diseases. Plant Pathol. 41:657-660.

16. Hughes, G., and Madden, L. V. 1993. Using the beta-binomial distribution to describe aggregated patterns of disease incidence. Phytopathology 83:759-763.

17. Hughes, G., and Madden, L. V. 1994. Aggregation and incidence of disease: Some implications for sampling. Asp. Appl. Biol. 37:25-31.

18. McCoy, R. E., and Dimock, A. W. 1973. Environmental factors regulating ascospore discharge by Mycosphaerella ligulicola. Phytopathology 63:586-589.

19. McCoy, R. E., Horst, R. K., and Dimock, A. W. 1972. Environmental factors regulating sexual and asexual regulation by Mycosphaerella ligulicola. Phytopathology 62:1188-1195.

20. Madden, L. V. 1980. Quantification of disease progression. Prot. Ecol. 2:159-176.

21. Madden, L. V. 1989. Dynamic nature of within-field disease and pathogen distributions. Pages 96-126 in: Spatial Components of Plant Disease Epidemics. M. J. Jeger, ed. Prentice-Hall, Englewood Cliffs, NJ.

22. Madden, L. V., and Hughes, G. 1994. BBD-Computer software for fitting the beta-binomial distribution to disease incidence data. Plant Dis. 78:536-540.

23. Madden, L. V., and Hughes, G. 1995. Plant disease incidence: Distributions, heterogeneity, and temporal analysis. Annu. Rev. Phytopathol. 33:529-564.

24. Madden, L. V., Louie, R., Abt, J. J., and Knoke, J. K. 1982. Evaluation of tests for randomness of infected plants. Phytopathology 72:195-198.

25. Minogue, K. P., and Fry, W. E. 1983. Models for the spread of disease: Model description. Phytopathology 73:1168-1173.

26. Minogue, K. P., and Fry, W. E. 1983. Models for the spread of disease: Some experimental results. Phytopathology 73:1173-1176.

27. Neher, D. A., Reynolds, R. L., and Campbell, C. L. 1997. Analysis of disease progress curves using linear models. Pages 29-33 in: Exercises in Plant Disease Epidemiology. L. J. Francl and D. A. Neher, eds. The American Phytopathological Society, St. Paul, MN.

28. Nutter, F. W., Jr. 1997. Quantifying the temporal dynamics of plant virus epidemics: A review. Crop Prot. 16:603-618.

29. Nutter, F. W., Jr. 2001. Disease assessment. Pages 312-326 in: Encyclo- pedia of Plant Pathology. O. C. Maloy and T. D. Murray, eds. John Wiley \& Sons, New York.

30. Perry, J. N. 1995. Spatial analysis by distance indices. J. Anim. Ecol. 64:303-314

31. Perry, J. N. 1998. Measures of spatial pattern for counts. Ecology 79:1008-1017.

32. Perry, J. N., and Dixon, P. M. 2002. A new method to measure spatial association for ecological count data. Ecoscience 9:133-141.

33. Perry, J. N., Winder, L., Holland, J. M., and Alston, R. D. 1999. Red-blue plots for detection of cluster in count data. Ecol. Lett. 2:106-113.

34. Pethybridge, S. J., and Hay, F. S. 2001. Influence of Phoma ligulicola on yield and site factors on disease development in Tasmanian pyrethrum crops. Aust. Plant Pathol. 30:17-20.

35. Pethybridge, S. J., Hay, F. S., and Groom, T. 2003. Seasonal fluctuations associated with pyrethrum foliage in Tasmania. Aust. Plant Pathol. 32:223-230.

36. Pethybridge, S. J., and Turechek, W. W. 2003. Analysis of the association among three viruses infecting hop in Australia. Plant Pathol. 52:158-167.

37. Pethybridge, S. J., and Wilson, C. R. 1998. Confirmation of ray blight disease of pyrethrum in Australia. Aust. Plant Pathol. 27:45-48.

38. Punithalingam, E. 1980. Didymella chrysanthemi, CMI Descriptions of Pathogenic Fungi and Bacteria. No. 662, Kew, UK.

39. Ridout, M. S., and Xu, X.-M. 2000. Relationships between several quadrat-based statistical measures used to characterize spatial aspects of data on disease incidence. Phytopathology 90:568-575.

40. Taylor, L. R. 1961. Aggregation, variance and the mean. Nature (Lond.) 189:732-735.

41. Turechek, W. W., and Madden, L. V. 1999. Spatial pattern analysis of strawberry leaf blight in perennial production systems. Phytopathology 89:421-433

42. Turechek, W. W., and Madden, L. V. 1999. Spatial pattern analysis and sequential sampling for the incidence of leaf spot on strawberry in Ohio. Plant Dis. 83:992-1000.

43. Upton, G., and Fingleton, B. 1985. Spatial Analysis by Example, Vol. I. Point Pattern and Quantitative Data. John Wiley \& Sons, Chichester, West Sussex, England.

44. Van Maanen, A., and Xu, X.-M. 2003. Modelling plant disease epidemics. Eur. J. Plant Pathol. 109:669-682.

45. Walker, J., and Baker, K. F. 1983. The correct binomial for the chrysanthemum ray blight pathogen in relation to its geographical distribution. Trans. Br. Mycol. Soc. 80:31-38.

46. Winder, L., Alexander, C. J., Holland, J. M., Woolley, C., and Perry, J. N. 2001. Modelling the spatio-temporal response of predators to transient prey patches in the field. Ecol. Lett. 4:568-576.

47. Xu, X.-M., and Madden, L. V. 2003. Considerations for the use of SADIE statistics to quantify spatial patterns. Ecography 26:821-830.

48. Xu, X.-M., and Madden, L. V. 2004. Use of SADIE statistics to study spatial dynamics of plant disease epidemics. Plant Pathol. 53:38-49.

49. Xu, X.-M., and Ridout, M. S. 2000. Effects of quadrat size and shape, initial epidemics conditions, and spore dispersal gradient on the spatiotemporal statistics of plant disease. Phytopathology 90:738-750.

50. Xu, X.-M., and Ridout, M. S. 2001. Effects of prevailing wind direction on spatial statistics of plant disease epidemics. J. Phytopathol. 149: 155-166. 